\title{
Investigation of the Characteristics of Submicron-Structured Powder-Fabricated Cr50Ni50 Alloys via Different Hot-Press Sintering Pressures
}

\author{
Shih-Hsien Chang ${ }^{1, *}$, Cheng-Liang Liao ${ }^{1}$, Kuo-Tsung Huang ${ }^{2}$ and Ming-Wei Wu ${ }^{1}$ \\ ${ }^{1}$ Department of Materials and Mineral Resources Engineering, National Taipei University of Technology, \\ Taipei 10608, Taiwan, R. O. China \\ ${ }^{2}$ Department of Auto-Mechanics, National Kangshan Agricultural Industrial Senior High School, Kaohsiung 82049, Taiwan, R. O. China
}

In this study, two different compositions of submicron-structured chromium and nickel powders are mixed to fabricate Cr50Ni50 alloys by vacuum hot-press sintering. The research imposes various hot-press sintering pressures (12, 24, 36 and $48 \mathrm{MPa}$ ), while the temperature is maintained at $1275^{\circ} \mathrm{C}$ for $1 \mathrm{~h}$, respectively. The experimental results show the optimum parameters of the hot-press sintered Cr50Ni50 alloys to be $1275^{\circ} \mathrm{C}$ at $48 \mathrm{MPa}$ for $1 \mathrm{~h}$. The relative density reaches $96.29 \%$, and the hardness and electrical conductivity increase to $75.2 \mathrm{HRA}$ and $2.01 \times$ $10^{4} \mathrm{Scm}^{-1}$, respectively. Simultaneously, the transverse rupture strength (TRS) value increases to $1109 \mathrm{MPa}$. Moreover, the Cr50Ni50 alloys dramatically acquire a more homogeneous microstructure, and the mean grain size decreases to $3.48 \mu \mathrm{m}$. Consequently, it is shown that hotpress sintering has a positive influence on the sintering behavior and improves the performance of the refractory metals. [doi:10.2320/matertrans.M2015400]

(Received October 26, 2015; Accepted March 2, 2016; Published April 25, 2016)

Keywords: Cr50Ni50 alloy, hot-press pressing, electrical conductivity, hardness, TRS

\section{Introduction}

Nanomaterials have received much recent attentions because they are expected to be used in various applications based on their excellent and unique optical, electrical, magnetic, biological, or mechanical properties. ${ }^{1)}$ The advantages of application of chromium-nickel alloys as structural, thin film resistors and device materials have been already recognized for decades. Chromium alloyed with iron and cobalt is appreciated particularly due to their high oxidation, corrosion and heat resistance, as well as the excellent creep strength at high temperatures. ${ }^{2-5}$

Powder metallurgy $(\mathrm{P} / \mathrm{M})$ methods offer two different types of materials with the objective of achieving higher strength, hardness and wear resistance etc. Conventional P/M involves mixing the metal powders, compacting of the mixed powders into molds and then sintering of the compact powders under the different atmospheres. ${ }^{6,7)} \mathrm{P} / \mathrm{M}$ technology is the conventional process for the production of $\mathrm{Cr}-\mathrm{Ni}$ alloys. On the other hand, hot-press sintering technique as a common technique was performed to fabricate the bulk bodies of the alloys. The hot-press sintering is another special $\mathrm{P} / \mathrm{M}$ technology, which directly pressed and sintering the material through a graphite mold to transmit the pressure to the powders. It can obtain the dense material at relatively lower sintering temperature. ${ }^{8-11)}$ Therefore, it is a novel technique to produce the $\mathrm{Cr}-\mathrm{Ni}$ alloys.

Previous study indicated that a hot pressing produced Nanometer WC-Co powder can lower the sintering temperature by about $100^{\circ} \mathrm{C}$, increases the density (more than 99\%) and circumscribes the growth of grain size (smaller than $1 \mu \mathrm{m}$ ) of alloys. Besides, hot pressing is an effective method to get WC-Co cemented carbides with fine grain size and good properties. ${ }^{12)}$ Other literature also pointed out that the dense microstructure of the $\mathrm{W} / \mathrm{Cu}-\mathrm{Al}_{2} \mathrm{O}_{3}$ composites is consisted of the matrix of the $\mathrm{Al}_{2} \mathrm{O}_{3}$ dispersion strengthened cop-

*Corresponding author, E-mail: changsh@ntut.edu.tw per base and the reinforced phase of homogeneous distributed W particles after hot-press sintering. The composite has relative theoretical density of $99.8 \%$. The bend fracture mechanism is brittle cleavage and interface separation. ${ }^{13)}$ However, a novel technology for fabricating $\mathrm{Cr}-\mathrm{Ni}$ composite materials needed to be further investigated.

In this work, a Cr-Ni alloy was produced by means of the vacuum hot-press sintering process and the solid-phase sintering of powder metallurgy technology. The effects of submicron-structured powders and hot-press sintering pressures on the Cr50Ni50 alloys were our chief concerns. A series of experiments on the hot-press sintered specimens were simultaneously carried out to explore the sintering behaviors and properties of the $\mathrm{Cr} 50 \mathrm{Ni} 50$ alloys. The influences of the microstructural features on the mechanical and electrical properties were investigated.

\section{Experimental Procedure}

In this study, $99.95 \%$ submicron-structured chromium and nickel powders were mixed and underwent hot-press sintering to fabricate the Cr50Ni50 alloys. A Microtrac X 100 laser was used to analyze the particle size of the submicron-structured powders. The mean particle size of the gas-atomized chromium and nickel powders was about $588 \pm 21$ and $610 \pm$ $33 \mathrm{~nm}$, respectively. Generally speaking, the morphology of gas-atomized powders tends toward an obvious round shape. Moreover, gas-atomized powders possess an excellent forming mechanism and sintering characteristics because the particles have a relatively smooth surface. ${ }^{8)}$

This study explored various pressures of hot-press sintering for Cr50Ni50 alloys and examined the effects on the microstructure, mechanical properties and electrical behavior. The hot-press sintering temperature was maintained at $1275^{\circ} \mathrm{C}$ for $1 \mathrm{~h}$ (the optimal sintering temperature). Various pressures $(12,24,36$ and $48 \mathrm{MPa})$ were employed in order to investigate the effect on the hot-press sintering characteristics of the Cr50Ni50 alloys. To evaluate the sintered behavior of 
the Cr50Ni50 alloys via various hot-press sintering (Yu Tai Vacuum Co., Ltd. HPS-1053) pressures, the porosity, hardness, transverse rupture strength (TRS) tests, electrical tests and microstructure observations were performed. Microstructural features of the specimens were examined by X-ray diffraction (XRD, Rigaku D/Max-2200) and scanning electron microscopy (Hitachi-S4700). Porosity tests followed the ASTM B311-08 and C830 standards.

The hardness of the specimens was measured by Rockwell indenter (HRA, Indentec 8150LK) with loading of $588.6 \mathrm{~N}$, which complied with the ASTM B294 and ASTM B163-11 standard methods. The Hung Ta universal material test machine (HT-9501A) with a maximum load of $245 \mathrm{kN}$ was used for the TRS tests (ASTM B528-05). Meanwhile, $R_{\mathrm{bm}}$ was the transverse rupture strength, which determined as the fracture stress in the surface zone. $F$ was maximum fracture load, $L$ was $30 \mathrm{~mm}, k$ was chamfer correction factor (normally 1.00 1.02 ), b and h were $5 \mathrm{~mm}$ in the equation $R_{\mathrm{bm}}=3 F L k / 2 b h^{2}$, respectively. The specimen dimensions of the TRS test were $5 \times 5 \times 40 \mathrm{~mm}^{3}$. Moreover, it needs to slightly grind the surface of the specimen and tests at least three pieces. A fourpoint probe (LRS4-TG2) was used to measure sheet resistance. In addition, electrical conductivity $(\sigma)$ was calculated according to the following formula: ${ }^{14,15)}$

$$
\rho=\mathrm{R} / t=1 / \sigma
$$

Where the $\rho$ is electrical resistivity, $\mathrm{R}$ is the resistance, $t$ is the thickness of the test sheet, and $\sigma$ is the electrical conductivity $\left(\mathrm{Scm}^{-1}\right)$, respectively.

\section{Results and Discussion}

Figure 1 shows the XRD patterns of the Cr50Ni50 alloys following hot-press sintering at different pressures. The major diffractions appeared in the $\mathrm{Cr}$ (110) and Ni (111), (200) and (220) planes, respectively. According to our previous studied $^{16)}$, the intensity of $\mathrm{Cr}$ (110) of Cr50Cu50 alloys were obviously enhanced as the pressure of the hot-pressed sintering increased. Generally, the main densification mechanism of hot-pressed sintering included the initial diffusion creep of high temperature and plastic deformation during the sintering step. When hot-pressed sintering entered the sintering stage,

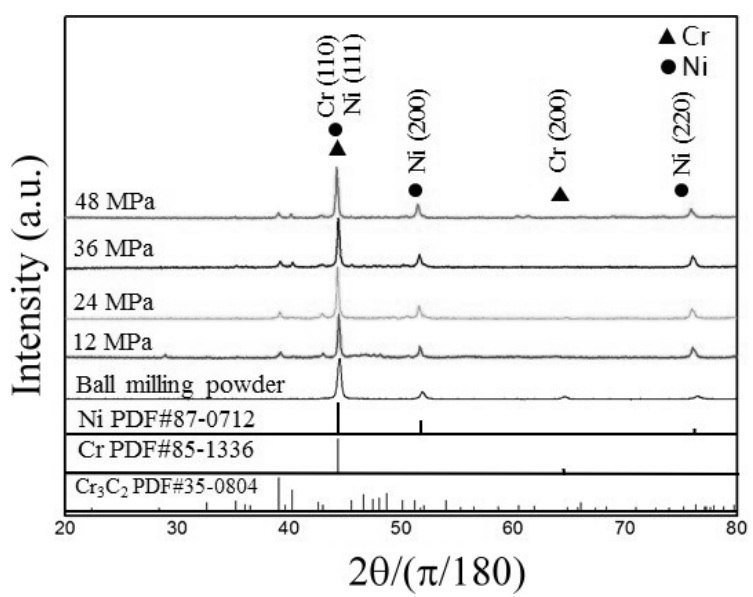

Fig. 1 XRD patterns of Cr50Ni50 alloys by hot-press sintering at different pressures. the assistance in high compressing stress led to effective plastic deformation and compaction results. Consequently, it is reasonable to suggest that an increase in sintering-pressure which contributed to the overall improvement of the crystalline. As a result, the alloy began to effectively generate plastic deformation and compaction. Therefore, as the sintering-pressure increasing, the results increased the lattice diffraction of the unit area and enhanced the relative intensity. In this work, the intensity of $\mathrm{Cr}$ (110) and $\mathrm{Ni}$ (111) was enhanced as the pressure of the hot-press sintering increased. $\mathrm{The} \mathrm{Cr}_{3} \mathrm{C}_{2}$ diffractions ( $2 \theta$ was $39.58^{\circ}$ and $42.96^{\circ}$, respectively) clearly appeared in the Cr50Ni50 alloys following the hot-press sintering process. It is reasonable to speculate that the chromium produced a chemical reaction with the carbon of the graphite mold, whereby the $\mathrm{Cr}_{3} \mathrm{C}_{2}$ compounds were generated. Besides, all the specimens obviously possessed a good crystalline property after hot-press sintering at different pressures. As the pressure increased $(12 \rightarrow 24 \rightarrow 36 \rightarrow 48 \mathrm{MPa})$, the intensity of the $\mathrm{Ni}$ (200) plane displayed a slight variation, as shown in Fig. 1.

There were two possible reasons to explain the phenomenon. Firstly, increasing the hot-press sintering pressure could effectively help and enhance the overall crystallinity of Cr50Ni50 alloys. It was reasonable to assume that the amount of $\mathrm{Cr}$ atoms solid-solution in the Ni phase of Ni50Cr50 alloys increased as the pressure increased. This meant that an increase of the $\mathrm{Cr}$ content in the Ni-rich phases resulted in a larger lattice constant, and further improved the deformability, and a slight variation in intensity of Ni (200). Secondly, the higher pressure could easily generate compaction and deformation of Ni-rich phases, which made the lattice diffraction of unit area and the intensity of Ni (200) plane vary. Actually, the main densification mechanism of hot-press sintering included the initial diffusion creep of high temperature and plastic deformation during the sintering steps. When hot-press sintering entered the sintering stage, the assistance in high compressing stress led to effective plastic deformation and compaction results. ${ }^{8,11,16)}$ Thus, the higher pressure of hot-press sintering easily led lattice diffraction of the unit area to vary and enhance the relative intensity, as shown in Fig. 2. Significantly, increasing the pressure of the hot-press sintering contributed to the overall improvement of the crystalline, and thus improved the microstructures and properties

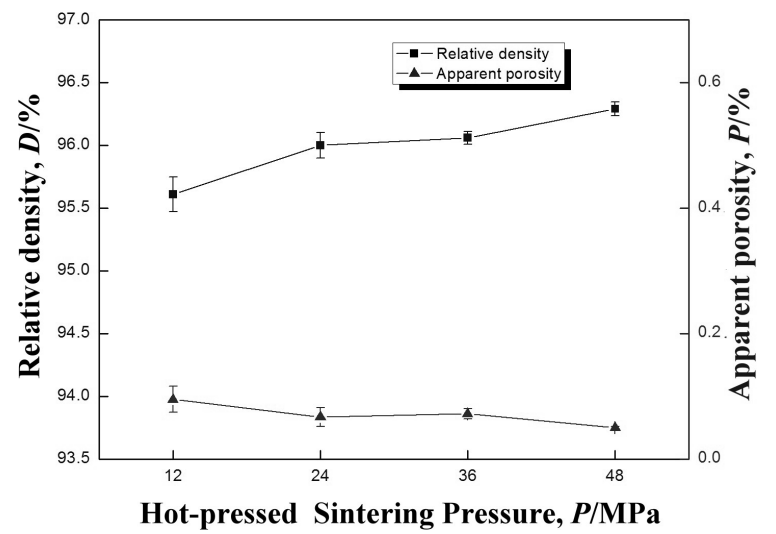

Fig. 2 Comparison of the relative density and apparent porosity of Cr50Ni50 alloys by hot-press sintering at different pressures. 

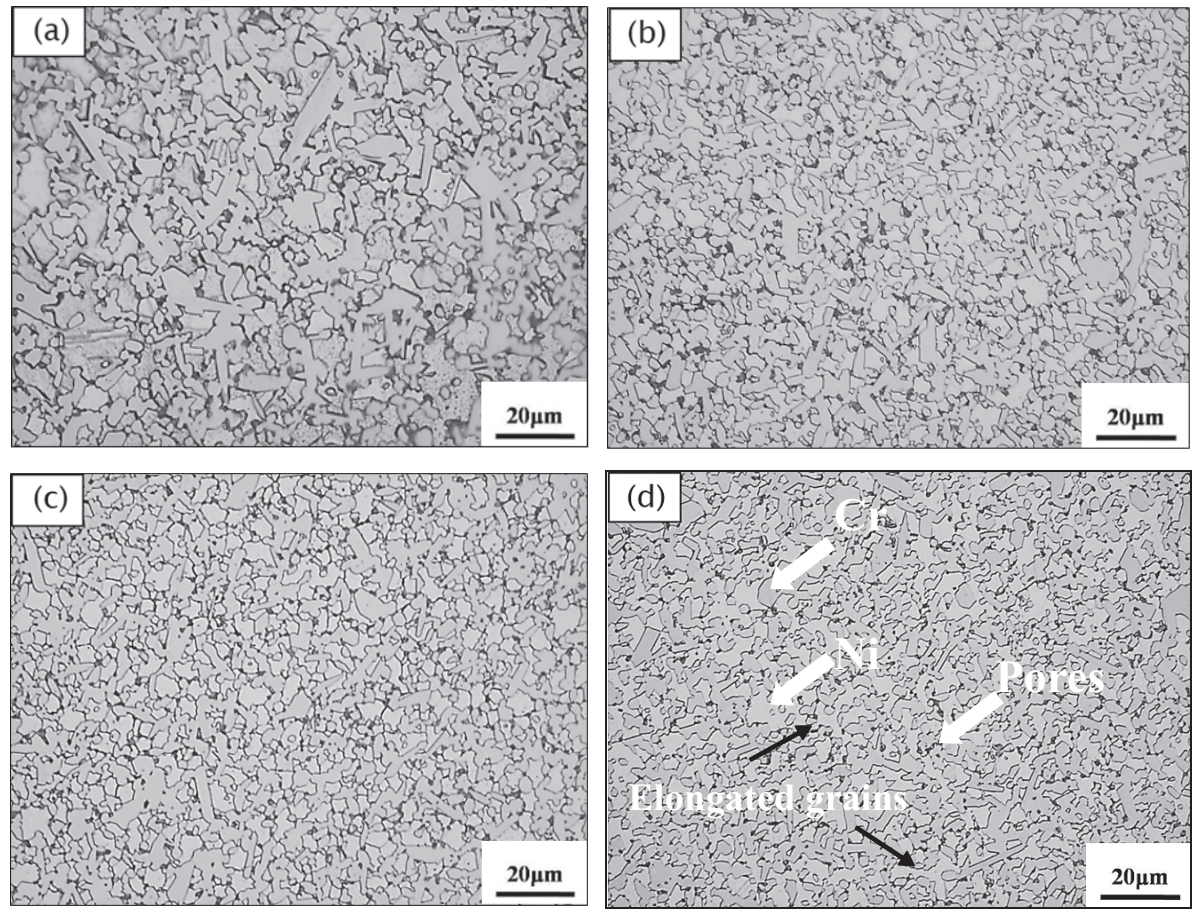

Fig. 3 OM morphology observations of Cr50Ni50 alloys by hot-press sintering at different pressures (a) 12 MPa, (b) 24 MPa, (c) $36 \mathrm{MPa}$, and (d) $48 \mathrm{MPa}$.

of the Cr50Ni50 alloys.

Figure 2 shows the relative density and apparent porosity of the Cr50Ni50 alloys after hot-press sintering at different pressures. The lowest relative density $(95.61 \%)$ appeared after $1275^{\circ} \mathrm{C}, 12 \mathrm{MPa}, 1 \mathrm{~h}$ hot-press sintering, and the highest relative density $(96.29 \%)$ occurred after $1275^{\circ} \mathrm{C}, 48 \mathrm{MPa}$ for $1 \mathrm{~h}$. From the sintering theory and technological points of view, usually during the final stages of sintering process, the porosities rapidly reduced and grain size significantly growth. Generally speaking, the sintered density of hot-press sintering was greater than $92 \%$ theoretical density. In this study, the relative density equals to $\mathrm{D} / \mathrm{D}_{\text {th }} \times 100 \%$; where the $\mathrm{D}$ was the sintered density and $\mathrm{D}_{\text {th }}$ was the theoretical density of specimens, respectively. In the final stage of hot-pressing sintering, porosity should be eliminated. This can only happen if all pores are connected fast, short diffusion paths along grain boundaries. For this to happen, the pores must follow the movement of grain boundaries. If discontinuous grain growth occurs then pores become trapped inside large grains. These pores are difficult to remove due to diffusion paths being long and slow, as lattice diffusion is the controlling mechanism. Open porosity effectively hinders grain boundary migration. Furthermore, the open porosity cluster loses stability, forming closed spherical or ellipsoidal pores, which are located in triple junctions. ${ }^{17)}$ As a result, increase the pressure of the hot-press sintering only slightly increased the relative density of the specimens, while the apparent porosity level was inversely proportional to the relative density. The apparent porosity had a slight declining trend as the pressure of the hotpress sintering increased. The lowest apparent porosity (0.05\%) appeared after $1275^{\circ} \mathrm{C}, 48 \mathrm{MPa}, 1 \mathrm{~h}$ hot-press sintering. In this work, the melting point of $\mathrm{Ni}$ was $1455^{\circ} \mathrm{C}$ and that of $\mathrm{Cr}$ was $1907^{\circ} \mathrm{C}$. However, the sintering was carried out at a temperature of $1275^{\circ} \mathrm{C}$, so only a $67 \%$ melting point $\left(\mathrm{T}_{\mathrm{m}}\right)$ of $\mathrm{Cr}$ and an $88 \%$ of $\mathrm{Ni}$ were reached, respectively. As the sin- tering temperature did not meet the eutectic point of the $\mathrm{Cr}-\mathrm{Ni}$ alloy $\left(1345^{\circ} \mathrm{C}\right)$, it was not possible to reach the liquid-phase sintering (LPS) temperature of the Cr50Ni50 alloys. Thus, the sintering properties were poorer than that of pure $\mathrm{Cr}$ or $\mathrm{Ni}$ metal, as a result of the solid-phase bonding. Meanwhile, it could be assumed that internal pores mainly existed in the grain boundaries and the necks of the incompletely sintered $\mathrm{Cr}$ and $\mathrm{Ni}$ phases (as shown in Fig. 3). Moreover, the sintering density of the Cr50Ni50 alloys increased, mainly due to the compaction of the $\mathrm{Cr}$ and $\mathrm{Ni}$ phases via the enhanced pressure. The results were further confirmed by means of a microstructural inspection.

Figure 3 shows the OM morphology observations of the Cr50Ni50 alloys after hot-press sintering at different pressures. Particularly, there were two different phases uniformly distributed in the sintered specimens, the white parts are the nickel-rich grains and the gray parts are the chrome-rich grains (as indicated by the arrows), as shown in Fig. 3(d). In addition, Fig. 3(a) clearly shows that dramatically closed pores still remained in the grain boundaries of the $\mathrm{Cr} 50 \mathrm{Ni} 50$ alloys after sintering at $1275^{\circ} \mathrm{C}, 12 \mathrm{MPa}$ for $1 \mathrm{~h}$. Thus, the interaction bonding between the phase-boundaries of the Cr50Ni50 specimens was relatively weak, resulting from the incomplete densification during sintering. However, the porosities obviously decreased as the sintering pressure ( $24 \rightarrow$ $36 \rightarrow 48 \mathrm{MPa}$ ) increased, as shown in Figs. 3(b)-3(d). Moreover, the grain size showed a slight decrease, from 5.05 to $3.45 \mu \mathrm{m}(12 \rightarrow 48 \mathrm{MPa})$. It was possible to say that the porosities decreased and no measurable grain growth was observed, which were mainly contributed to by the plastic deformation $\mathrm{Ni}$ phase and the compaction of chromium particles via enhanced pressure. Although it was hard to observe the plastic deformation of Ni phase in Fig. 3, it can clearly be found that the compacted Ni phases were elongated (black arrows), and had a tendency to surround the $\mathrm{Cr}$ phases after the higher hot- 
(a)

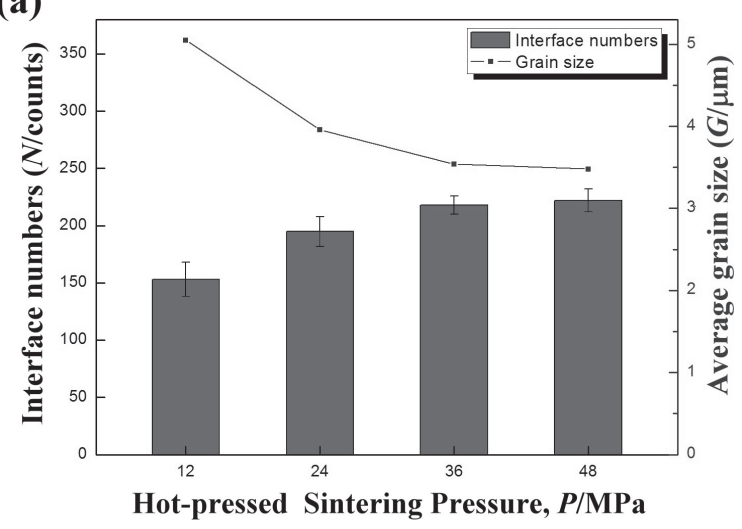

(b)

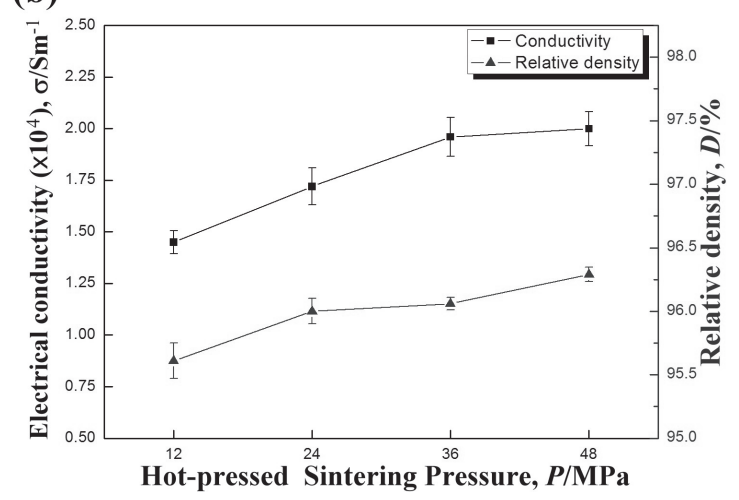

Fig. 4 Comparison of the properties of Cr50Ni50 alloys by hot-press sintering at different pressures (a) interface numbers and grain size, and (b) electrical conductivity and relative density.

press sintering (48 MPa), as shown in Fig. 3(d). As a result, increasing the pressure of hot-press sintering was effective in improving the compaction of $\mathrm{Ni}$ and $\mathrm{Cr}$ phases, and pores decreased and no grain decreased and no grain growth happened in the final stage of densification. The result also agreed with the previous literature. ${ }^{8)}$

Figure 4(a) shows the relation between the interface numbers and grain sizes of the Cr50Ni50 alloys after hot-press sintering at different pressures. The interface numbers seemed to be reversely proportional to the grain sizes. Increasing the pressure $(12 \rightarrow 24 \rightarrow 36 \rightarrow 48 \mathrm{MPa})$ of the hot-press sintering resulted in a decrease in grain size $(5.05 \rightarrow 3.96 \rightarrow 3.54 \rightarrow$ $3.48 \mu \mathrm{m})$, and the interface numbers also increased $(153 \rightarrow$ $195 \rightarrow 218 \rightarrow 222$ ), as shown in Fig. 4(a). In the research, the interface numbers were calculated by the overall interface numbers of the cross chromium/nickel alloys in the unit length of BEI images. Previous literature indicated that a structure with more interface numbers had a better microstructure and mechanical properties. ${ }^{8}{ }^{8)}$ In fact, the structure is related with physical and mechanical properties of material. Normally the good microstructure significantly possesses better properties. It means that the more interface numbers will result in the better mechanical properties. Notably, the interface numbers of the $\mathrm{Cr} 50 \mathrm{Ni} 50$ alloys showed an obvious increase as the pressure of the hot-press sintering increased. Furthermore, the smallest value (153) of interface numbers appeared in $12 \mathrm{MPa}$ hot-press sintering. As the pressure increased, the interface numbers rapidly increased. The highest value (222) of interface numbers appeared in the $1275^{\circ} \mathrm{C}$, $48 \mathrm{MPa}, 1 \mathrm{~h}$ sintered specimens, as shown in Fig. 4(a). It is reasonable to speculate that the $48 \mathrm{MPa}$-sintered specimens possessed a relatively small grain size and consistent structure, which was helpful to the meticulous microstructure and mechanical properties.

In addition, the electrical resistivity measurement is a useful tool when investigating the various phenomena in solids. It is an easy and inexpensive technique, which can be used in the study of phase transformations, impurities, defects and other structural changes in crystalline and amorphous metals/ alloys. ${ }^{19)}$ Figure 4 (b) shows the electrical conductivity and relative density of the $\mathrm{Cr} 50 \mathrm{Ni} 50$ alloys after hot-press sintering at different pressures. It can be clearly seen that the electrical performance and the relative density of the sintered Cr50Ni50 alloys exhibited similar trends. When the pressure of the hot-press sintering increased, both the electrical conductivity and relative density showed obvious increases. In this work, the relative density of the sintered $\mathrm{Cr} 50 \mathrm{Ni} 50$ alloys increased to $96.29 \%$, while the electrical conductivity value increased to $2.01 \times 10^{4} \mathrm{Scm}^{-1}$ after the $1275^{\circ} \mathrm{C}, 48 \mathrm{MPa}, 1 \mathrm{~h}$ hot-press sintering treatments. A previous study has also proven the relationship of the relative density of Cr-based alloys to the electrical properties. ${ }^{20)}$ Increasing the relative density significantly improved the electrical properties of the $\mathrm{Cr}$ based alloys. Thus, it could be inferred that the higher relative density and lower porosity of the hot-press sintered Cr50Ni50 alloys led to the increase in the mean free path of the electrons, which improved the electrical performance. As mentioned previously, the internal closed pores of the sintered specimens were significantly reduced after high-pressure hotpress sintering treatments (Fig. 3). Consequently, increasing the pressure effectively enhanced the relative density and improved the electrical properties of the hot-press sintered Cr50Ni50 alloys.

Figure 5 shows the hardness and TRS of the hot-press sintered Cr50Ni50 alloys at different pressures. The hardness slightly increased as the pressure of the hot-press sintering increased, as shown in Fig. 5(a). Previous literature also revealed a positive relationship between the hardness and the relative density. ${ }^{6,8)}$ The hardness was significantly enhanced as the sintering density increased. The literature also shows that decreasing the porosities of sintered materials effectively enhances plastic deformation resistance and hardness. $\left.{ }^{8,21}\right)$ Generally, the higher pressures of solid-phase sintering (SPS) helped improve the plastic deformation of the $\mathrm{Cr} 50 \mathrm{Ni} 50$ alloys, resulting in the higher hardness. In this study, increasing the pressure $(12 \rightarrow 48 \mathrm{MPa})$ of the hot-press sintered specimens resulted in an obvious increase in the relative density $(95.61 \rightarrow 96.29 \%)$, which in turn resulted in the high hardness $(73.3 \rightarrow 75.2 \mathrm{HRA})$. Also, the grain size decreased as the pressure of the hot-press sintering increased. As the load increased, the smaller grains possessed a greater area fraction of grain boundaries along the line of the mobile dislocations. Therefore, the number of dislocation tangles was greater, and they were strong enough to hold the mobile dislocations, which was advantageous to the hardness and strength. This result also agreed with our previous findings. ${ }^{20)}$

Figure 5(b) shows the TRS tests of the hot-press sintered Cr50Ni50 alloys at different pressures. Previous studies have 
indicated that as the relative density increases, the higher density provides stronger binding to protect the rupture mechanism of generation. ${ }^{6,8,15)}$ In the present research, increasing
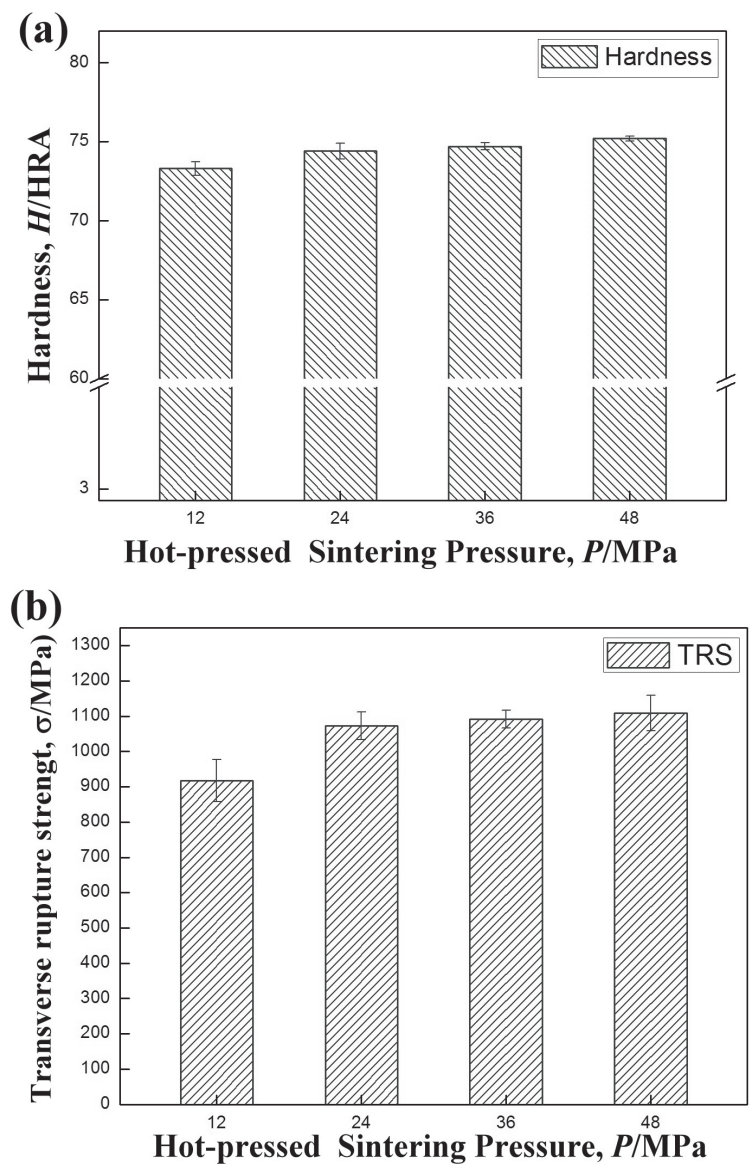

Fig. 5 Comparison of the mechanical properties of Cr50Ni50 alloys by hotpress sintering at different pressures (a) hardness, and (b) TRS tests. the pressure $(12 \rightarrow 48 \mathrm{MPa})$ of the hot-press sintering significantly improved the relative density $(95.61 \rightarrow 96.29 \%)$ and decreased the grain size $(5.05 \rightarrow 3.48 \mu \mathrm{m})$ of the $\mathrm{Cr} 50 \mathrm{Ni} 50$ alloys. Moreover, the above experimental results suggest that if a structure has more interface numbers, the microstructure presents a better structure. Therefore, the TRS value showed an obvious increase as the pressure was increased. The highest TRS value (1109 $\mathrm{MPa})$ appeared in the $1275^{\circ} \mathrm{C}, 48 \mathrm{MPa}$, $1 \mathrm{~h}$ hot-press sintered Cr50Ni50 alloys, the higher bonding strength of which hindered the generation of the rupture mechanism. In our previous studied ${ }^{6)}$, the relative density, electrical conductivity, hardness and TRS of $1325^{\circ} \mathrm{C}, 1 \mathrm{~h}$ vacuum sintered Cr50Ni50 alloys was $90.93 \%, 2.13 \times 10^{3} \mathrm{Scm}^{-1}$, 59.6 HRB and 232.2 $\mathrm{MPa}$, respectively. Furthermore, the $1345^{\circ} \mathrm{C}, 1 \mathrm{~h}$ vacuum sintered $\mathrm{Cr} 50 \mathrm{Ni} 50$ alloys was $98.67 \%$, $2.33 \times 10^{3} \mathrm{Scm}^{-1}, 63.8 \mathrm{HRA}$ and $454.3 \mathrm{MPa}$, respectively. In this work, the $1275^{\circ} \mathrm{C}, 48 \mathrm{MPa}, 1 \mathrm{~h}$ hot-press sintered Cr50Ni50 alloys underwent lower sintering temperature and higher pressure. The relative density was slightly decline to $96.29 \%$, however the effective compaction and lower sintering temperatures (avoid the grain coarsening phenomenon under high temperatures) resulted in the better properties. Significantly, the electrical conductivity enhanced to $2.01 \times$ $10^{4} \mathrm{Scm}^{-1}$, hardness increased to $75.2 \mathrm{HRA}$ and TRS reached $1109 \mathrm{MPa}$. The results confirmed that the hot-pressing was effective in improving sintering properties.

Figure 6 shows the fractographs of the Cr50Ni50 alloys after hot-press sintering at different pressures. The fracture fractographs of the different hot-press sintered specimens look to be almost the same type. Generally, the brittle fracture surface possesses a relatively flat fracture surface, as show in Fig. 6(a). Conversely, the ductility fracture is one half of a microvoid that formed and then separated during the fracture process. It could be found the difference and consist of numbers spherical "dimple" fractures, as show in Fig. 6(b). For all
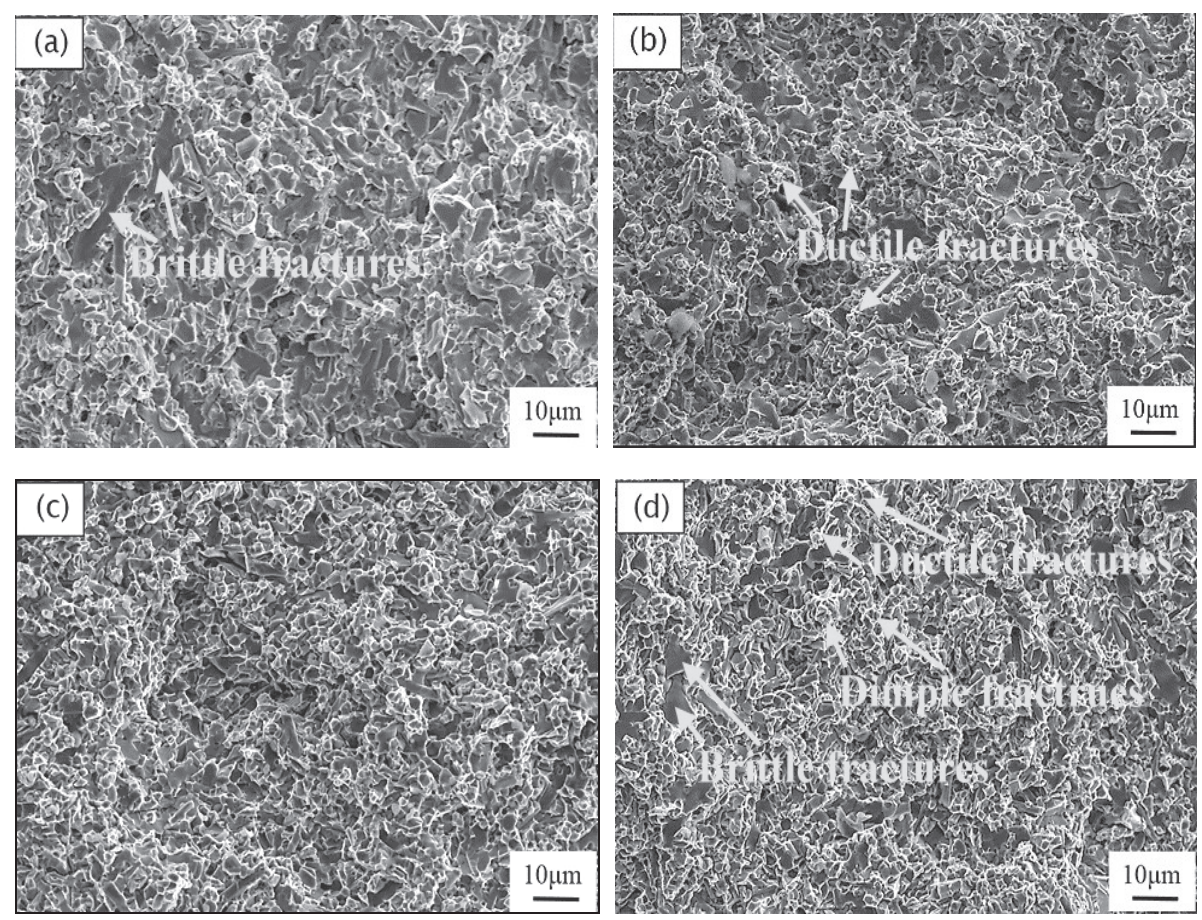

Fig. 6 Fractographs observation of the Cr50Ni50 alloys by hot-press sintering at different pressures (a) $12 \mathrm{MPa}$, (b) $24 \mathrm{MPa}$, (c) $36 \mathrm{MPa}$, and (d) $48 \mathrm{MPa}$. 


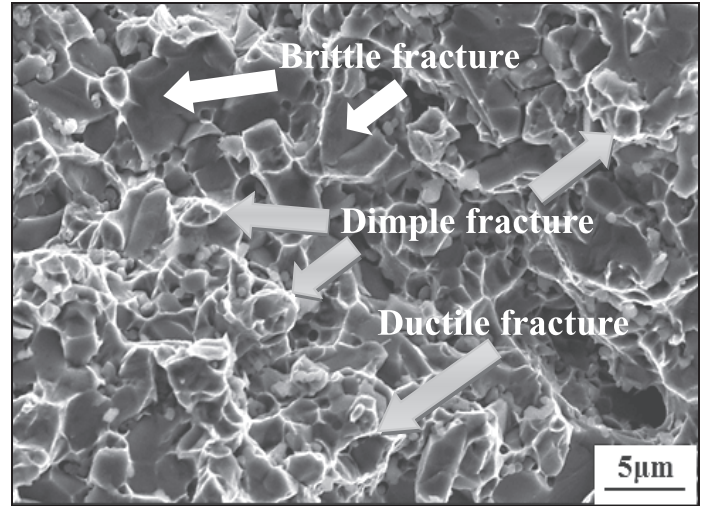

Fig. 7 High-magnification fractographs observation of the Cr50Ni50 alloys after $1275^{\circ} \mathrm{C}$ and $48 \mathrm{MPa}$ hot-press sintering for $1 \mathrm{~h}$.

the specimens it was found that both ductile and brittle fractures (as shown the arrows of Fig. 6(d)) coexisted in the Cr50Ni50 alloys after the TRS tests, as shown in Figs. 6(a)(d). Taking the specimen of hot-press sintering at $36 \mathrm{MPa}$ as an example, ductile fractures, dimple fractures and brittle fractures can be observed, as shown in Fig. 7. Besides, there were many small pores uniformly distributed in the fracture surface. As the load increased, the pores easily generated the points of stress concentration and formed a continuous rupture. Most of the pores located in the grain boundaries caused the small cracks along the grains of the material to form an intergranular brittle fracture. The results can be further compared with Fig. 6. Figures 6(a) and 6(b) show more fractographs of the brittle fractures, while Figs. 6(c) and 6(d) show the fractographs of ductile and dimple fractures. The porosity level was a main factor in affecting the TRS value. In addition, the nickel phase provided toughness and generated the dimple fractures in the material. However, as the pressure of the hot-press sintering increased, the average grain size showed a slight decrease, with SEM fractographs the fracture surface generating the refinement trend. It is reasonable to speculate that the grain refinement was another factor which could improve the strength of the hot-press sintered specimens. Significantly, more ductile and dimple fractures appeared in the $1275^{\circ} \mathrm{C}, 48 \mathrm{MPa}, 1 \mathrm{~h}$ hot-press sintered specimens, as shown in Fig. 6(d). According to the discussion and results, the optimal hot-press sintering pressure for the Cr50Ni50 alloys was $48 \mathrm{MPa}$. Consequently, a uniform microstructure and excellent electrical conductivity and mechanical properties were obtained.

\section{Conclusions}

The microstructural analysis and mechanical tests showed that the hot-press sintering process was effective in eliminat- ing the internal closed pores of the sintered specimens; thus, high-density and high-strength $\mathrm{Cr} 50 \mathrm{Ni} 50$ alloys were acquired. In this work, the relative density of the $\mathrm{Cr} 50 \mathrm{Ni} 50$ alloys reached $96.29 \%$ and the electrical conductivity increased to $2.01 \times 10^{4} \mathrm{Scm}^{-1}$ after $1275^{\circ} \mathrm{C}, 48 \mathrm{MPa}, 1 \mathrm{~h}$ hot-press sintering. Significantly, the optimal SPS process was effective in eliminating the internal pores of the Cr50Ni50 alloys, which resulted in ideal electrical and mechanical performances. In addition, increasing the pressure $(12 \rightarrow 48 \mathrm{MPa})$ of the hotpress sintering process no measurable grain growth was observed, which resulted in a slight decreased in the average grain size $(5.05 \rightarrow 3.48 \mu \mathrm{m})$. Consequently, the highest hardness (75.2 HRA) and highest TRS values (1109 MPa) were obtained.

\section{Acknowledgments}

This research is supported by the ASSAB STEELS TAIWAN CO., LTD. The authors would like to express their appreciations for Dr. Harvard Chen.

\section{REFERENCES}

1) M. Khajepour and S. Sharafi: Powder Technol. 232 (2012) 124-133.

2) Y. Harada, M. Ohmori, F. Yoshida and R. Nowak: Mater. Lett. 57 (2003) 1142-1150.

3) N. Espallargas and S. Mischler: Wear 270 (2011) 464-471.

4) V. Petley, S. Sathishkumar, K.H. Thulasi Raman, G. Mohan Rao and U. Chandrasekhar: Mater. Res. Bull. 66 (2015) 59-64.

5) M. Danışman and N. Cansever: J. Alloy. Compd. 493 (2010) 649-653.

6) S.H. Chang, J.C. Chen, K.T. Huang and J.K. Chen: Trans. JIM 54 (2013) 1034-1039.

7) S.H. Chang and S.L. Chen: J. Alloy. Compd. 585 (2014) 407-413.

8) C. Liang, S.H. Chang, J.R. Huang, K.T. Huang and S.T. Lin: Trans. JIM 56 (2015) 1127-1132.

9) Z.H. Qiao, X.F. Ma, W. Zhao, H.G. Tang and B. Zhao: J. Alloy. Compd. 462 (2008) 416-420.

10) X.M. Duan, D.C. Jia, Z.L. Wu, Z. Tian, Z.H. Yang, S.G. Wang and Y. Zhou: Scr. Mater. 68 (2013) 104-107.

11) S.H. Chang and P.Y. Chang: Mater. Sci. Eng. A 618 (2014) 56-62.

12) C. Jia, L. Sun, H. Tang and X. Qu: Int. J. Refract. Met. Hard Mater. 25 (2007) 53-56.

13) B.H. Tian, X.W. Zhang, R.L. Zhao, Y. Liu, S.G. Jia and F.Z. Ren: Rev. Adv. Mater. Sci. 33 (2013) 219-223.

14) W. D. Callister JR and D. G. Rethwisch: Materials Science and Engineering, $9^{\text {th }}$ ed. John Wiley and Sons Pte Ltd., 2014, pp. 681-683.

15) S.H. Chang, S.H. Chen and K.T. Huang: Trans. JIM 54 (2013) 18571862.

16) S.H. Chang, C. Liang, J.R. Huang and K.T. Huang: Powder. Metall. (2015) in press (DOI:10.1080/00325899.2015.1132033).

17) A. Rafferty, T. Prescott and D. Brabazon: Ceram. Int. 34 (2008) 15-21.

18) H.S. Huang, I.T. Hong, H.G. Dong and C.H. Chiu: Bull. Powder Metall. Assoc. 35 (2010) 161-167.

19) A.A. Al-Aql: Mater. Des. 24 (2003) 547-550.

20) S.H. Chang, S.H. Chen and K.T. Huang: Trans. JIM 53 (2012) 16891694.

21) S.H. Chang, M.H. Chang and K.T. Huang: J. Alloy. Compd. 585 (2014) 407-413. 